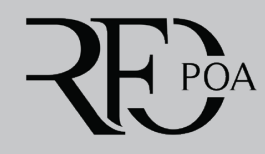

\title{
Cirurgia do periápice para remoção DE LESÕES GRANULOMATOSAS: RELATO DE CASO
}

\author{
Periapical surgery to remove granulomatous lesion: case report
}

\author{
(DSidinéia Feitoza de Jesus a, (D) Yasmim Santos Meneses a, (DRafaela Cardoso de-Sáa, \\ Vanessa Valente Elias ${ }^{a}$, (D) Marcio Santos de Carvalhob , (DAlexandra Mussolino de Queiroz ${ }^{b}$, \\ (D)Francisco Wanderley Garcia de Paula e Silva ${ }^{b}$, (D) Manoel Damião Sousa Neto ${ }^{c}$.
}

\section{RESUMO}

Granuloma periapical é um termo histológico que refere-se à formação de uma massa de tecido granulomatoso ao redor do ápice de um dente, decorrente da inflamação e necrose do tecido pulpar. É constituído por um infiltrado de células inflamatórias como macrófagos, plasmócitos e linfócitos, além de fibroblastos, fibras colágenas e capilares. A cirurgia do periápice é uma alternativa para preservação do dente na cavidade bucal nos casos em que a inflamação periapical é persistente mesmo após tratamento dos canais radiculares. O objetivo desse trabalho é relatar um caso clínico no qual a técnica cirúrgica do periápice foi utilizada para remoção de lesões granulomatosas de uma paciente, do sexo feminino, com histórico de abscesso periapical recidivante sem sintomatologia dolorosa na região dos dentes anteriores superiores 11, 12 e 13. O exame histopatológico demonstrou a presença de um tecido granulomatoso com intenso infiltrado inflamatório misto, permeado com linfócitos e elevado número de plasmócitos, confirmando o diagnóstico de granuloma periapical. O tratamento foi considerado exitoso, visto que a paciente se manteve asintomática e houve incorporação do enxerto ósseo bovino inorgânico e início da neoformação óssea na região periapical.

Palavras-chave: Doença crônica. Granuloma periapical. Tecido de Granulação.

\begin{abstract}
Periapical granuloma is a histological term that refers to the formation of a mass of granulomatous tissue around the apex of a tooth resulting from inflammation and necrosis of the pulp tissue. It consists of an infiltrate of inflammatory cells such as macrophages, plasmocytes and lymphocytes, as well as fibroblasts, collagen fibers and capillaries. Periapical surgery is an alternative for preserving the tooth in the oral cavity in cases where periapical inflammation is persistent even after treatment of root canals. The objective of this study was to report a clinical case in which the surgical technique was used to remove granulomatous lesions from a patient, female, with a history of recurrent periapical abscess without painful symptomatology in the region of the anterior 11,12 and 13 teeth. The histopathological exam demonstrated the presence of a granulomatous tissue with intense inflammatory infiltrate mixed, permeated with lymphocytes and high number of plasmocytes, confirming the diagnosis of periapical granuloma. The treatment was considered successful since the patient remained asymptomatic and there was incorporation of the inorganic bovine bone graft and initiation of bone neoformation in the periapical region.
\end{abstract}

Keywords: Chronic disease. Periapical granuloma. Granulation tissue.

\footnotetext{
${ }^{a}$ Instituto Amazônia de Ensino Superior, IAES - Manaus, AM, Brasil.

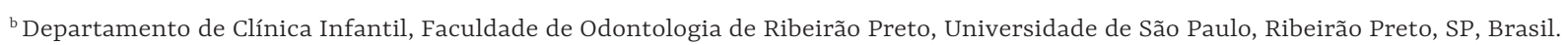

${ }^{\mathrm{c}}$ Departamento de Odontologia Restauradora, Faculdade de Odontologia de Ribeirão Preto, Universidade de São Paulo, Ribeirão Preto, SP, Brasil.
}

Autor de correspondência: Marcio Santos de Carvalho - E-mail: marsantcar@gmail.com

Data de envio: 06/05/2020 | Data de aceite: 16/07/2020 


\section{INTRODUÇÃO}

As lesões periapicais são definidas como uma resposta imunoinflamatória localizada, desencadeada pela infecção de microrganismos no sistema de canais radiculares ${ }^{1,2}$. Essa proliferação microbiana quando não tratada resulta em necrose do tecido pulpar seguida de reabsorções ósseas e dos tecidos dentais². Essas lesões tem características osteolíticas e podem ser classificadas em cistos radiculares, granulomas periapicais e abscessos periapicais, provenientes da contaminação dos microrganismos e seus produtos/subprodutos no sistema de canais radiculares ${ }^{2-4}$.

O diagnostico diferencial das lesões periapicais é realizado por meio de análises histopatológicas ${ }^{3}$. A prevalência das lesões osteolíticas, obtidas a partir dessas análises revela uma ampla variação no acometimento destas patologias. Os cistos periapicais ocorrem em 22 a $55,5 \%$ dos casos e os granulomas em 2,5 a $59,3 \%$. O granuloma periapical refere-se a uma massa de tecido granulomatoso ao redor do ápice de um dente, decorrente da inflamação e necrose do tecido pulpar. É constituído por um infiltrado de células inflamatórias como macrófagos, plasmócitos e linfócitos, além de fibroblastos, fibras colágenas e capilares ${ }^{3,6}$.

Os cistos radiculares também tem origem inflamatória e representam o mais comum dentre os cistos odontogênicos. São caracterizados por uma cavidade patológica com revestimento epitelial com um lúmen, contendo líquido e restos celulares ${ }^{3,6}$. Essas lesões podem ser originadas de um granuloma que se tornou epitelizado, devido à proliferação de remanescentes epiteliais na região do periápice ${ }^{3,6,7}$.

Inicialmente, a técnica indicada para o tratamento de dentes com polpa irreversivelmente inflamada ou necrosada é o tratamento endodôntico radical, que envolve a remoção do conteúdo do canal radicular seguido pela obturação. Em casos de recidiva, há indicação da remoção cirúrgica da lesão localizada no periápice ${ }^{8}$, cujos métodos incluem curetagem perirradicular, ressecção de raiz e apicectomia, seguidas de preparação e retro-obturação do canal radicular ${ }^{9,10}$.

Para indicação da cirurgia perirradicular, deve-se avaliar cada caso individualmente e levar em consideração a anatomia da região e os riscos que a abordagem cirúrgica implica ${ }^{11}$. Paralelamente, deve-se proceder à eliminação de microrganismos e zonas de imperfeições apicais e a obliteração adequada dos túbulos dentinários expostos com o corte radicular, manobras de fundamental importância para o sucesso do procedimento ${ }^{9,12}$.

Após o procedimento cirúrgico, deve-se acompanhar o processo de reparação dos tecidos removidos. O princípio da cicatrização das feridas periapicais após o procedimento cirúrgico é semelhante à cicatrização de uma ferida do tecido conjuntivo de outras regiões do corpo. É um acontecimento planejado que se inicia com a hemostasia, seguido pela inflamação, fase proliferativa, remodelação e reparo ${ }^{13}$. Os biomateriais produzidos em laboratórios podem ser usados para auxiliar o reparo de defeitos ósseos extensos e devem ser biocompatíveis e de fácil manuseio ${ }^{14}$.

O objetivo do caso clínico é relatar a técnica cirúrgica do periápice para remoção de lesões granulomatosas de uma paciente do sexo feminino com histórico de abscesso periapical recidivante na região dos dentes anteriores superiores 11, 12 e 13, sem sintomatologia dolorosa. O estudo foi aprovado pelo Comitê de Ética em Pesquisa, sob o número 30865820.0.0000.5419. 


\section{RELATO do CASO}

Paciente L.P.D.F, 23 anos, sexo feminino, residente de Manaus, Amazonas, Brasil, compareceu à clínica odontológica da Faculdade do Amazonas (IAES), relatando histórico de abscesso dento-alveolar, com edema no lado direito da face, na região dos dentes anteriores, porém sem sintomatologia dolorosa. Durante o exame intrabucal, foram observadas alterações na mucosa gengival e grande abaulamento nas regiões vestibular e palatina dos dentes 11, 12 e 13. A paciente apresentou resposta negativa para os testes de percussão vertical e horizontal e teste de sensibilidade pulpar ao frio. Sob a hipótese diagnóstica de granuloma periapical, a técnica de escolha para o tratamento de lesões periapicais extensas e com necessidade de avaliação histólogica foi à cirurgia perirradicular.

Exames complementares foram solicitados para realizar o tratamento odontológico como exames laboratoriais, hemograma completo, coagulograma e teste glicêmico, mostrando valores dentro da normalidade. Foram realizados exames por imagens para auxiliar no diagnóstico e na realização do tratamento: radiografia periapical convencional e tomografia computadorizada de feixe cônico (Figura 1), onde observou o estabelecimento de lesões periapicais através de imagem radiolúcida ao redor dos dentes avaliados.

O tratamento endodôntico convencional prévio dos três dentes com sistema Rotatório (Protaper, Pirassununga/SP, Brasil); e na obturação o cone de guta-percha (WaveOne, Gold Conform FitTM Gutta-Percha, Pirassununga/SP, Brasil), foi introduzido a $1 \mathrm{~mm}$ além do ápice radicular para melhor localização do forame apical no ato cirúrgico.
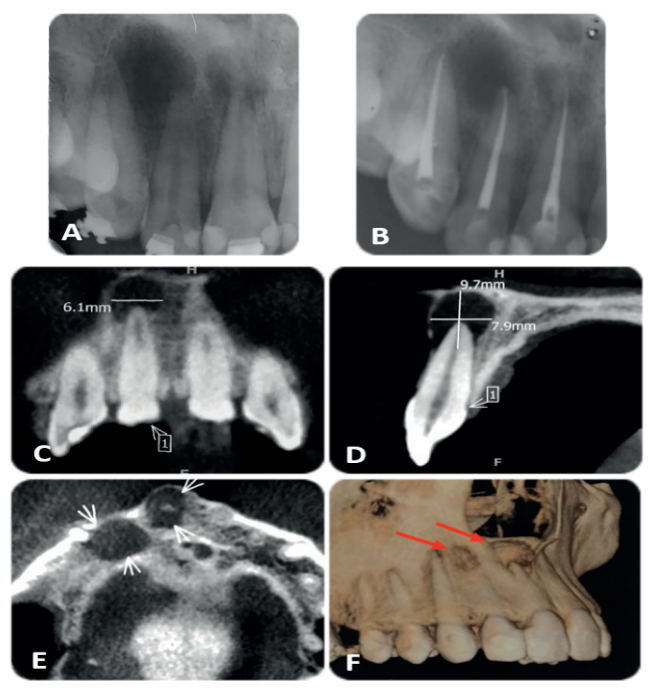

Figura 1: Exames complementares: Radiografias Periapicais: A) radiografia periapical inicial; B) radiografia periapical após a conclusão do tratamento endodôntico. Tomografia inicial: C) corte coronal;

D) corte sagital; E) corte axial; F) reconstrução 3D.

Para remover o processo inflamatório periapical, o tratamento endodôntico foi associado com a cirurgia perirradicular, usando a técnica de apicectomia e curetagem, a fim de, eliminar os microrganismos, seus produtos e subprodutos. Inicialmente para o controle de inflamação foi prescrita Dexametasona (4mg)(EMS, S. B. do Campo/SP, Brasil), uma hora antes do procedimento cirúrgico. A antissepsia da cavidade bucal foi realizada com digluconato de clorexidina a $0,12 \%$, posteriormente foi realizada anestesia local do paciente, o anestésico de escolha foi a Mepivacaína 3\% com adrenalina 1:100.000 (Nova DFL ${ }^{\circledR}$, Jacarepaguá/RJ, Brasil), por meio da técnica do bloqueio do nervo infraorbitário direito e esquerdo, e bloqueio do 
nervo nasopalatino. Foi escolhida a técnica de Ochsenbein-Luebke foi escolhida para realizar a incisão e retalho mucoperiosteal. Após o deslocamento do retalho, a osteotomia foi realizada com broca carbide para osso ( $\mathrm{n}^{\mathrm{o}} .8$ SS Rio de Janeiro/RJ, Brasil) acoplada em caneta de alta rotação sob irrigação contínua com soro fisiológico para a exposição da loja cirúrgica.

As lesões perirradiculares foram removidas por meio da curetagem periradicular com o auxílio da pinça (Kolcher Reta) e de curetas de Lucas (Golgram, São Caetano do Sul/ SP, Brasil). A lesão apresentou uma coloração branco-acastanhada e foi encaminhada para o laboratório de histopatológica em solução de formol tamponado a 10\%. A apicectomia foi realizada em um ângulo de $45^{\circ} \mathrm{com}$ broca carbide tronco-cônica número 701 (KG Sorensen, Cotia/SP, Brasil), seguida pela obturação retrógrada com agregado de trióxido mineral (MTA) (Angelos, Londrina/PR, Brasil) (Figura 2).
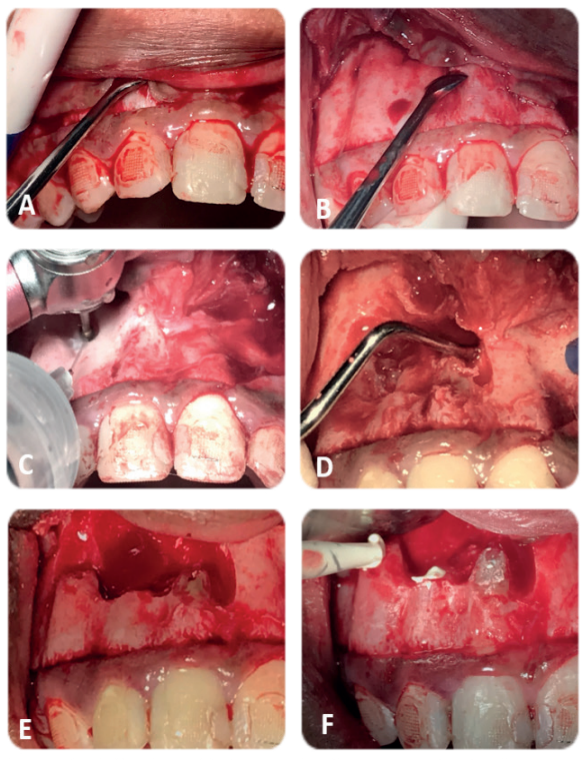

Figura 2: (A, B) Técnica cirúrgica, descolamento da mucosa alveolar com descolador de Molt; C) osteotomia para exposição dos ápices radiculares; D) curetagem da lesão;

E) apicectomia em 45 graus; F) aplicação do MTA.

O procedimento operatório foi finalizado com enxerto ósseo na região, com a finalidade de preencher o espaço ocupado pela lesão, proteger o ápice radicular e promover a reparação do tecido ósseo. A loja cirúrgica foi preenchida com osso bovino inorgânico (LuminaBoni, Granulação Média, Critéria, São Paulo/SP, Brasil) manipulado com soro fisiológico. Em seguida foi recortada e posicionada uma membrana absorvível biológica bovina (Lumina-Coat, Critéria, São Paulo/SP, Brasil), garantindo uma reparação óssea guiada. O retalho cirúrgico foi reposicionado e a sutura foi realizada com pontos simples com fio de nylon (3.0 - Technew, Rio de Janeiro/RJ, Brasil) (Figura 3). 

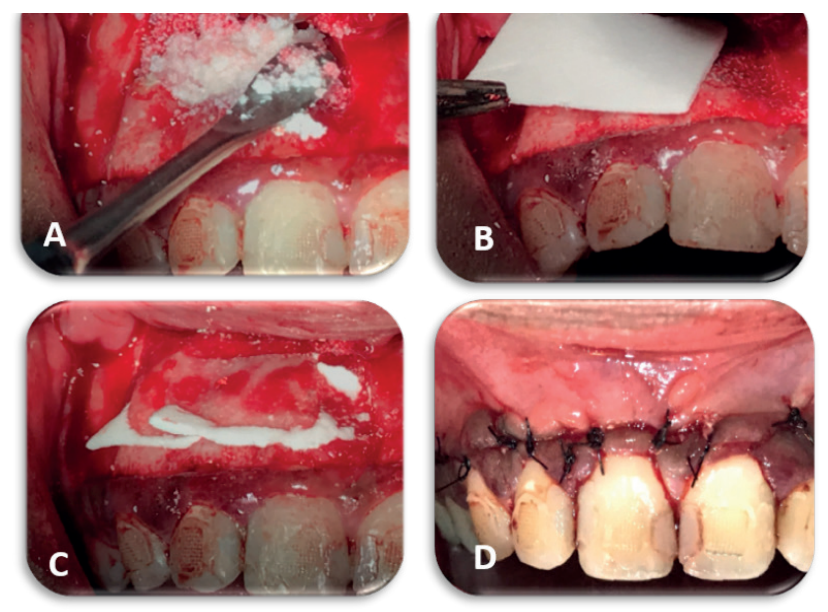

Figura 3: A) Acomodação do biomaterial manipulado; (B, C) membrana biológica sendo acomodada; D) sutura.

A paciente foi instruída em relação aos cuidados pós-operatórios, e orientada sobre a importância da manutenção da higiene bucal, além da adesão dos medicamentos prescritos, sendo eles: amoxicilina (500mg) por via oral, a cada 8 horas, durante cinco dias, nimesulida (100mg) por via oral a cada 12 horas durante quatro dias e paracetamol (750mg), por via oral, a cada 6 horas, nas primeiras 24 horas ou enquanto houvesse dor. As suturas foram removidas uma semana após a cirurgia e os tecidos moles apresentaram boa cicatrização e ausência de abaulamento.

No exame histopatológico, observou-se a presença de um tecido granulomatoso com intenso infiltrado inflamatório misto permeado com linfócitos e elevado número de plasmócitos, confirmando o diagnóstico de granuloma periapical.

No período de seis meses após a intervenção cirúrgica, a tomografia computadorizada de feixe cônico (Figura 4) foi observado uma regressão da lesão periapical. Ao exame clínico de palpação, observou-se ausência de abaulamento nas regiões de mucosa vestibular e palatina dos dentes afetados e ausência de sintomatologia dolorosa.

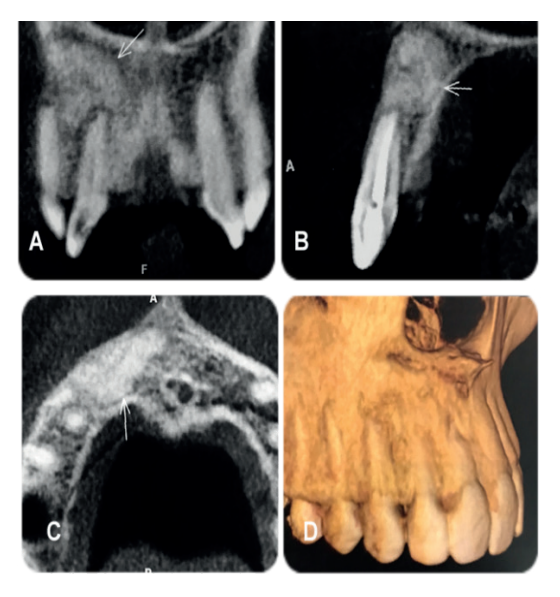

Figura 4: Tomografia após 6 meses; A) corte coronal; B) corte sagital; C) corte axial; D) reconstrução 3D. 


\section{Dıscussão}

A cirurgia do periápice é uma das opções de tratamento em casos de lesões extensas e recidivantes, que não regridem com o tratamento endodôntico convenciona $1^{12}$. O procedimento cirúrgico empregado, por sua vez, possibilita a remoção do infiltrado inflamatório crônico na região periapical e viabiliza o reparo ${ }^{15}$. No caso relatado, a lesão periapical aconteceu em decorrência da doença cárie que comprometeu os tecidos pulpares dos dentes.

A literatura tem mostrado a constante evolução das técnicas para tratamento endodôntico ${ }^{16,17}$. Entretanto, existem casos em que o prognóstico da terapia endodôntica convencional ou do retratamento dos canais radiculares não são favoráveis ${ }^{12}$. Em geral, a primeira escolha para o tratamento de granuloma periapical é a terapia endodôntica convencional, entretanto em casos de lesões extensas o tratamento cirurgico é indicado ${ }^{3}$. A realização da técnica cirúrgica do periápice pode ser uma alternativa para promover o reparo dos tecidos mineralizados, sempre considerando os riscos na abordagem cirúrgica, visando a manutenção do dente na cavidade bucal ${ }^{11,12,18}$. Dessa forma, diante de complicações anatômicas, intercorrências no tratamento convencional e necessidade de avaliação histopatológica, a cirurgia do periápice está indicada ${ }^{19}$.

Em virtude da extensão da lesão e necessidade de avaliação histopatológica do caso relatado, optou-se pela cirurgia perirradicular, convergindo com a literatura científica ${ }^{19}$. Foi realizada apicectomia e curetagem perirradicular a fim de promover o reparo da região periapical ${ }^{12}$, associada com regeneração tecidual guiada (RTG), utilizando enxertos de substituição óssea capazes de melhorar a qualidade do reparo ${ }^{13,20}$. Ainda nesse contexto, no tecido dental, revisões sistemáticas apontam a utilização de agregado de trióxido mineral (MTA) como material retrobturador para preenchimento das raízes, tendo em vista suas propriedades de biocompatibilidade, baixa toxicidade e capacidade seladora desejadas para cirurgia do periápice ${ }^{21,22}$.

As imagens por Tomografia Computadorizada auxiliam no diagnóstico e acompanhamento em casos de cirurgia perirradicular ${ }^{23}$. O tempo decorrido entre a finalização do tratamento e a presença de evidências radiográficas do processo cicatricial devem ser determinantes para confirmar o sucesso ou insucesso da terapêutica. Nesse estudo, o reparo tecidual foi identificado através da incorporação do enxerto e início da neoformação óssea, verificada aos seis meses de acompanhamento pós-operatório, concordando com os achados anteriores ${ }^{24}$.

Haja vista a regressão das lesões e a constatação da neoformação óssea no caso relatado, considera-se que o tratamento proposto foi exitoso, promovendo a manutenção do tecido ósseo e dos tecidos dentais mineralizados, garantindo as funções do dente na cavidade bucal.

\section{Conclusão}

A cirurgia perirradicular é uma alternativa para o tratamento de lesões periapicais extensas visando a manutenção dos dentes na cavidade bucal. A remoção cirúrgica, associada ou não ao emprego de biomateriais, é segura e eficaz possibilitando a neoformação do tecido ósseo periapical. 


\section{REFERÊNCIAS}

1. Paula-Silva FW, da Silva LA, Kapila YL. Matrix metalloproteinase expression in teeth with apical periodontitis is differentially modulated by the modality of root canal treatment. ] Endod. 2010;36(2):231-7.

2. Graves DT, Oates T, Garlet CP. Review of osteoimmunology and the host response in endodontic and periodontal lesions. J Oral Microbiol. 2011 Jan 17;3:5304.

3. Neville BW. Doença pulpar e periapical. In: Neville BW, Damm DD, Allen CM, Chi AC, editores. Patologia oral e maxilofacial. Rio de Janeiro: Elsevier; 2016. p. 252-3.

4. Paula-Silva FWG, Ribeiro-Santos FR, Petean IBF, Arnez MFM, Almeida-Junior LA, Carvalho FK, et al. Root canal contamination or exposure to lipopolysaccharide differentially modulate prostaglandin E2 and leukotriene B4 signaling in apical periodontitis. J Appl Oral Sci. 2020;28: e20190699.

5. Bacaltchuk M, Cumerlato ML, Zardo P, Luisi SB, Rados PV, Barbachan J]D. A avaliação da prevalência de lesões periapicais examinadas no laboratório de patologia bucal da PUC nos anos de 1973, 1983, 1993 e 2003. Rev Odonto Ciênc. 2005;20(50):324-9.

6. American Association of Endodontists. Glossary of Endodontic Terms. 20. ed. Chicago: Tenth Edition; 2020. p. 15. [acesso 2020 ago 25] Disponível em: https://www.aae.org/specialty/clinical-resources/glossary-endodontic-terms/.

7. Neto MN, Danesi CC, Daniele TU. Contribution to the study of radicular cyst. literature review. Saúde. 2004;30 (1-2):90-9.

8. Dias ACS, Maltos KLM, Aguiar EG. Tratamento endodôntico transcirúrgico: uma opção para casos especiais. Rev cir traumatol buco-maxilo-fac. 2010;10(2):49-53.

9. Chandler NP, Koshy S. The changing role of the apicectomy operation in dentistry.] R Coll Surg Edinb. 2002;47(5):660-7.

10. European Society of Endodontology. Quality guidelines for endodontic treatment: consensus report of the European Society of Endodontology. Int Endod J. 2006;39(12):921-30.

11. Kraus RD, von Arx T, Gfeller D, Ducommun ], Jensen SS. Assessment of the nonoperated root after apical surgery of the other root in mandibular molars: a 5-year follow-up study. J Endod. 2015 Apr;41 (4):442-6.

12. Orso VA, Sant'ana Filho M. Cirurgia paraendodôntica: quando e como fazer. Rev Fac Odontol Porto Alegre. 2006;47(1):20-3.

13. Lin L, Chen MY, Ricucci D, Rosenberg PA. Guided tissue regeneration inperiapical surgery. J Endod. 2010 Apr;36(4):618-25

14. Bezerra F]. Terapia clínica avançada em Implantodontoa. São Paulo: Artes Médicas; 2002. p. 21

15. Lodi LM, Poleto S, Soares RG, Irala LED, Salles AA, Limongi O. Cirurgia paraendodôntica: relato de caso clínico. Revista Sul-Brasileira de Odontologia. 2008;5(2):69-74.

16. Kishen A, Peters OA, Zehnder M, Diogenes AR, Nair MK. Advances in endodontics: potential applications in clinical practice. J Conserv Dent. 2016;19(3):199-206.

17. Iandolo A, landolo G, Malvano M, Pantaleo G, Simeone M. Modern technologies in Endodontics. G Ital Endod. 2016;30(1):2-9.

18. Silva RA, Buosi MP, Nascimento VR, Pfau EA, Tomazinho LF. Cirurgia parendodôntica associada a enxerto ósseo de biomaterial (Bio Oss Collagen): Relato de Caso. Brazilian Journal of Surgery and Clinical Research. 2013;5(1):34-8.

19. Bramante CM, Berbert A. Cirurgia Paraendodôntica. 1. ed. São Paulo: Santos; 2000. p.131

20. Bernabé PF, Azuma MM, Ferreira LL, Dezan-Júnior E, Gomes-Filho]E, Cintra LT. Root reconstructed with mineral trioxide aggregate and guided tissue regeneration in apical surgery: a 5-year follow-up. Braz Dent ]. 2013;24(4):428-32.

21. Serrano-Giménez M, Sánchez-Torres A, Gay-Escoda C. Prognostic factors on periapical surgery: A systematic review. Med Oral Patol Oral Cir Bucal. 2015 Nov 1;20(6):e715-22.

22. Küçükkaya Eren S, Parashos P. Adaptation of mineral trioxide aggregate to dentine walls compared with other root-end filling materials: a systematic review. Aust Endod ]. 2019 Apr;45(1):111-21.

23. Shekhar V, Shashikala K. Cone beam computed tomography evaluation of the diagnosis, treatment planning, and long-term followup of large periapical esions treated by endodontic surgery: two case reports. Case Rep Dent. 2013;2013:564392.

24. Almeida-Filho ], Almeida GM, Marques EF, Bramante CM. Cirurgia paraendodôntica: relato de caso. Oral Sci. $2011 \mathrm{jan} / \mathrm{dez} ; 3(1): 21-5$. 